\title{
O TRABALHO COMO CAMINHO AO ENSINO TÉCNICO INTEGRADO
}

\author{
EL TRABAJO COMO FORMA DE ENSEÑANZA TÉCNICA INTEGRADA
}

\author{
WORK AS A WAY TO INTEGRATED TECHNICAL TEACHING
}

\author{
Rafael Magalhães Costa ${ }^{1}$ \\ https://orcid.org/0000-0002-4678-255X \\ Maria José de Resende Ferreira ${ }^{2}$ \\ http://orcid.org/0000-0001-9442-0468 \\ Rogério Omar Caliari ${ }^{3}$ \\ http://orcid.org/0000-0003-4342-8392
}

\begin{abstract}
Resumo
O texto aborda resultados de pesquisa realizada pelo programa de Mestrado em Educação Profissional e Tecnológica em rede nacional. Analisa as contribuições da Oficina de Orientação Profissional desenvolvida junto aos concludentes do Ensino fundamental que frequentam o curso preparatório denominado de Pré-Ifes na cidade de Cachoeiro de Itapemirim - ES. Os aportes teóricos que fundamentam essa investigação estão atrelados aos campos de conhecimento Trabalho, Educação e Psicologia Social. Metodologicamente, optamos por uma pesquisa qualitativa com abordagem da pesquisa intervenção. Para produção dos dados, foram utilizadas as técnicas de questionários aos estudantes do $9^{\circ}$ ano e entrevistas com o Grupo Gestor do Ifes campus Cachoeiro de Itapemirim, além do uso de diário de campo durante todo o processo investigativo. Após a produção, implementação e validação da intervenção pedagógica, depreendemos que a Oficina de Orientação Profissional qualificou as atividades do projeto de extensão Ifes Portas Abertas, ofertado pelo campus cachoeirense, bem como subsidiou as escolhas estudantis no sentido de contribuir para o ingresso, permanência e êxito escolar dos estudantes junto ao curso técnico pleiteado.
\end{abstract}

Palavras-chave: Educação Profissional. Adolescência. Orientação Profissional.

\footnotetext{
${ }^{1}$ Mestrado em Educação Profissional e Tecnológica - Instituto Federal do Espírito Santo. Professor do Colegiado de História do Centro Universitário São Camilo-ES. E-mail: rafaelmagalhaes@saocamilo-es.br.

${ }^{2}$ Doutorado em Educação pela Universidade Federal do Espírito Santo. Professora do Instituto Federal do Espírito Santo e do ProfEPT. Grupo de Pesquisa: Núcleo 1 PPG-UFES da rede de Pesquisa UFG-UFES-UNB. Email: majoresende@yahoo.com.

${ }^{3}$ Doutorado em Educação pela Universidade Federal do Espírito Santo. Professor do Instituto Federal do Espírito Santo e do ProfEPT. Grupo de Pesquisa (CNPq): Culturas, Parcerias e Educação do Campo. E-mail: rogerio.caliari@ifes.edu.br.
}

\section{Como referenciar este artigo:}

COSTA, R. M.; FERREIRA, M.J. R.; CALIARI, R. O. O trabalho como caminho ao ensino técnico integrado. Revista Pedagógica, v. 23, p. 1-23, 2021. 


\title{
Resumen
}

El texto aborda los resultados de la investigación realizada por el programa de Maestría en Educación Profesional y Tecnológica en red nacional. Se analizan los aportes del Taller de Orientación Profesional desarrollado con los alumnos finalistas de la escuela primaria, que asisten al curso preparatorio denominado Pre-Ifes en la ciudad de Cachoeiro de Itapemirim ES. Los aportes teóricos que sustentan esta investigación están vinculados a los campos del Conocimiento, Trabajo, Educación y Psicología Social. Metodológicamente, optamos por una investigación cualitativa con enfoque de investigación de intervención. Para la producción de los datos, se aplicaron técnicas de cuestionario a estudiantes de $9^{\circ}$ grado y entrevistas con el Grupo de Gestión de Ifes en el campus Cachoeiro de Itapemirim, además del uso de diarios de campo durante todo el proceso investigatorio. Tras la producción, implementación y validación de la intervención pedagógica, encontramos que el Taller de Orientación Profesional calificó las actividades del proyecto de ampliación Ifes Portas Abertas, que ofrece el campus Cachoeirense, así como subvencionó las opciones de los estudiantes para contribuir al ingreso, permanente y éxito académico de los estudiantes con el curso técnico solicitado.

Palabras clave: Educación profesional. Adolescencia. Orientación profesional.

\begin{abstract}
The text approaches the results of research carried out by the Master's program in Professional and Technological Education on a national network (ProfEPT). It analyzes the contributions of the Professional Counselling Workshop developed with final-year middle school students, who attend the preparatory course called Pre-Ifes in the city of Cachoeiro de Itapemirim - ES. The theoretical contributions that support this investigation are linked to the knowledge fields of Work and Education and Social Psychology. Methodologically, we opted for a qualitative research with an intervention-research line of action. For data production, both questionnaire techniques and interviews were applied to gth grade students and Ifes Management Group on the Cachoeiro de Itapemirim campus respectively, in addition to the use of field diaries throughout the investigative process. After the production, implementation and validation of the pedagogical intervention, we found that the Professional Orientation Workshop not only certified Ifes Portas Abertas extension project activities, which is offered by Cachoeiro de Itapemirim campus, but also supported students' choices in order to contribute to the admission, permanence and academic success of students when applying for the intended technical course.
\end{abstract}

Keywords: Professional Education. Adolescence. Professional Counselling.

\section{INTRODUÇÃO}

A oferta da Educação Profissional Tecnológica de nível médio(EPT), promovida pela

Rede Federal de Educação Profissional, Científica e Tecnológica, composta por um conjunto de instituições de ensino, constitui-se numa ampla proposta de educação integral. Essa assume o desafio de formar o estudante numa abrangência que compreende o domínio tanto dos conhecimentos humanísticos quanto os dos técnicos ou tecnológicos. 
Intenta-se uma possibilidade de estudos que integrem todas as dimensões formativas, que potencialize a atuação das pessoas no mundo. Isso implica um processo intelectual e racional que oportuniza aos estudantes a produção de novos saberes, bem como o aprendizado das funções laborais para o exercício da profissão, como direito de todos os trabalhadores.

Essa proposta consubstancia-se na Lei de Diretrizes e Bases da Educação (LDB) nº 9.394/96, no Título I “Da Educação”, a qual estabelece que a Educação Escolar deve vincular-se ao mundo do trabalho e à prática social. Além disso, a proposta preconiza que o ensino deve ser baseado, dentre outros, no princípio do pluralismo de ideias e de concepções pedagógicas (BRASIL, 1996).

Os Institutos Federais de Educação, Ciência e Tecnologia (IFs), embasados na Lei nº 11.892/08 - que institui a Rede Federal de Educação Profissional, Científica e Tecnológica, assumem a formação humana e cidadã como um processo inerente à qualificação para o exercício da laboralidade, o desenvolvimento profissional com as dimensões da ciência, da tecnologia, da cultura e dos conhecimentos específicos (BRASIL, 2008). Nesse entendimento, a concepção do trabalho como princípio educativo emerge nos dispositivos destacados, corroborando o proposto na LDB ao afirmar que a educação deve abranger “[...] os processos formativos que se desenvolvem na vida familiar, na convivência humana, no trabalho, nas instituições de ensino e pesquisa, nos movimentos sociais e organizações da sociedade civil e nas manifestações culturais" (BRASIL, 1996).

Cientes do compromisso dos IFs de implementar parcerias com os Arranjos Produtivos Locais (APLs) ${ }^{4}$, com vistas à vivência profissional, atentamo-nos para a situação do discente concludente do Ensino Fundamental das redes pública e particular, interessado no ingresso nessas instituições. Destacamos algumas situações inerentes nesse contexto, tais como: a troca de ambiente estudantil, de professores, de currículo, práticas pedagógicas e avaliativas e as consequentes mudanças que isso acarreta no estudante. Mais precisamente, ressaltamos a necessidade de optar pelo curso técnico para seguir no seu processo de escolarização, especialmente com vistas à profissionalização, ação muitas

\footnotetext{
${ }^{4}$ São atividades cuja viabilidade estão relacionadas às possibilidades econômicas de uma determinada região, levando em consideração questões sociais e culturais, constituindo-se como uma das finalidades formativas do Ifes (IFES - PDI 2019-2024).
} 
vezes realizada sem o devido conhecimento prévio necessário do curso e da nova estrutura escolar.

Todo esse contexto ocorre na adolescência, período que a Psicologia Social a partir das proposições dos estudiosos desse campo, qualifica como um rito de passagem marcado por uma falta de consciência clara de si mesmo e de uma desconexão em relação às próprias necessidades, seja do ponto de vista emocional, material, psicossocial, etc. Isso ocasiona dificuldades em perceber e incorporar papéis sociais devido a "[...] complexidades e aspectos desconhecidos (a sociedade), onde o adolescente ainda carece de um lugar definido" (MÜLLER, 1988, p. 141).

Fazer escolhas demasiadamente importantes num período de imprecisões perante a si próprio e em relação à sociedade na qual esteja inserido, credita ao jovem um conjunto de certezas que ele, geralmente, não possui, o que demanda de suporte qualificado dos diversos grupos com os quais esse indivíduo interage. A escola, como uma das instituições protagonistas nesse processo, é uma potencial interlocutora, no sentido de consolidar propostas educativas que facilitem tais decisões estudantis.

Com o intento de auxiliar nesse momento de definição do prosseguimento do percurso escolar, o Instituto Federal do Espírito Santo (Ifes) campus Cachoeiro de Itapemirim, promove, desde 2009, um projeto de extensão denominado de Ifes Portas Abertas (IFES, 2009). Suas ações são destinadas ao público em geral e, particularmente, aos discentes do $9^{\circ}$ ano do Ensino Fundamental, para que conheçam a Instituição e possam dar subsídios às opções para a continuidade dos seus estudos.

As atividades desenvolvidas consistem numa visita ao campus, na apresentação do espaço físico, dos cursos, da proposta pedagógica institucional, entre outras ações. Nessa prática, entretanto, estão ausentes discussões orgânicas acerca do mundo do trabalho referentes aos cursos técnicos ofertados, como também articulação com áreas econômicas análogas, para aproximações junto à atividade profissional. Entendemos que essas abordagens são necessárias, devido à relação estreita que tais cursos possuem com o setor produtivo, pelas subjetividades dos estudantes e pelo amparo legal dessa oferta educacional (BRASIL, 1996).

Ainda a respeito da relação da escola com o mundo do trabalho, voltamo-nos para o Plano de Desenvolvimento Institucional (PDI) do Ifes 2019- 2024 (IFES, 2019), em especial 
no Projeto Pedagógico Institucional (PPI), que se fundamenta, teoricamente, na concepção do Trabalho como Princípio Educativo como perspectiva pedagógica perante a EPT. O referido documento postula que o Instituto

[...] se fundamenta na concepção de trabalho como princípio educativo que medeia a produção de existência e objetivação da vida humana ao articular atividades materiais e produtivas aos conhecimentos da ciência, da arte, da cultura, da técnica e da tecnologia, com a finalidade de orientar os processos formativos em toda a sua multidimensionalidade (IFES, 2019, p. 69).

É evidente que conhecer melhor o que se propõe a estudar, em especial as possibilidades de inserção no mundo do trabalho e as características profissionais que competem a esses trabalhadores, leva, a partir da nossa pesquisa, à necessidade de uma qualificação do projeto de extensão Ifes Portas Abertas. Além de municiar o futuro candidato de informações aprimoradas para um melhor conhecimento do itinerário formativo, o projeto pode consolidar-se numa estratégia com horizonte para a Orientação Profissional.

O programa televisivo Salto para o Futuro, que compõe a programação da TV Escola, trouxe no bojo do Boletim 18, de 2009, intitulado "Juventude e Escolarização: os sentidos do Ensino Médio" o reconhecimento da "[...] centralidade que o trabalho ocupa na vida dos jovens que estão no Ensino Médio (p.15)" e complementa que o trabalho garante "[...] condições sociais que Ihes permitam viver a condição juvenil (p.19)". Apesar de tratar-se de um tema importantíssimo aos estudantes, o citado programa fora destinado aos educadores.

$\mathrm{Na}$ busca de mais informações acerca de orientação das escolhas profissionais referentes aos cursos técnicos de nível médio, verificamos que o Ministério da Educação (MEC) disponibiliza o Catálogo Nacional de Cursos Técnicos (BRASIL, 2016). Esse é direcionado às instituições de Educação Profissional, a estudantes e à sociedade civil, no sentido de fornecer maiores explicações sobre os diferentes percursoseducativos. Cumpre a sua função listando, nominalmente, uma série de possibilidades profissionais, mas sem aprofundar nenhuma delas e, muito menos, numa propositiva de diálogo com os setores produtivos. 
A necessidade de por em prática as informações acerca das políticas públicas da Educação Profissional nesse cenário faz-se urgente, notadamente quando detectamos uma crescente procura pelos cursos ofertados pelo Ifes campus Cachoeiro de Itapemirim. Tais dados são disponibilizados por meio da divulgação dos resultados das inscrições feitas pelos discentes finalistas da segunda etapa da Educação Básica que querem ingressar nos cursos técnicos integrados. Outra comprovação dessa realidade é o aumento da procura pelos cursos preparatórios para entrada no Ifes sul capixaba, denominados de "Pré-Ifes".

A partir dessas discussões, o presente artigo explicita as contribuiç̧ões da Oficina de Orientação Profissional desenvolvida junto aos estudantes concluintes do Ensino Fundamental e cursistas do Pré-Ifes na cidade de Cachoeiro de Itapemirim-ES. Explora, ainda, as aproximações dos aportes conceituais dos campos de conhecimentos Trabalho, Educação e Psicologia Social. Na sequência, o texto apresenta a opção metodológica, os caminhos percorridos para a produção dos dados e a discussão dos resultados coletados pela pesquisa empírica. À guisa de finalização, sem a pretensão de concluir, mas de provocar novas reflexões acerca da experiência pedagógica, intentamos potencializar as ações do projeto de extensão Ifes Portas Abertas, além de contribuir com os adolescentes no momento de escolha para o prosseguimento da trajetória estudantil, fundamental na sua futura profissionalização.

\section{TRABALHO, EDUCAÇÃO E ADOLESCÊNCIA: APROXIMAÇÕES E DIÁLOGOS POSSÍVEIS}

$\mathrm{Na}$ busca da origem etimológica da palavra trabalho - tripalium, tomamos a definição de Carcanholo (2011), como instrumento de tortura utilizado para empalar prisioneiros de guerra e escravos fugidos. Segundo o autor, o sentido do trabalho vem sofrendo significativas alterações ao longo do tempo:

\footnotetext{
A origem do trabalho encontra-se na necessidade de a humanidade satisfazer suas necessidades básicas, evoluindo para os outros tipos de necessidades, mesmo supérfluas. Assim, trabalhar é produzir riqueza, o que é necessário em todos os modos de produção, seja no comunal primitivo, no escravista, no feudal, no capitalista ou nas experiências socialistas. O que muda é a forma de produzir, a tecnologia utilizada e a relação entre o sujeito que produziu e o que se apropria do que foi produzida; tal forma varia de acordo com o tipo de organização da sociedade (CARCANHOLO, 2011, p. 147).
} 
A concepção de trabalho, nesse texto, não se reduz às atividades laborais ou emprego, mas como condição humana, na dimensão da produção da existência nos mais diversos períodos históricos. Nesse sentido, afirma Kosik (1976, p.184):

O trabalho é procedimento ou ação em que de certo modo se constitui a unidade do homem e da natureza na base da sua recíproca transformação: o homem se objetiva no trabalho, e o objeto, arrancado do contexto natural original, é modificado e elaborado.

Marx e Engels (2007, p. 10) postularam que os homens se distinguiram dos animais “[...] logo que começam a produzir seus meios de existência, e esse passo à frente é a própria consequência de sua organização corporal. Ao produzirem seus meios de existência, os homens produzem indiretamente sua própria vida material”. O ser humano, a partir do trabalho, modificou a si mesmo e o ambiente que o cerca na busca da manutenção da vida comunitária.

\footnotetext{
Antes, o trabalho é um processo entre o homem e a natureza, um processo em que o homem, por sua própria ação, o, medeia, regula e controla seu metabolismo com a Natureza. Ele mesmo se defronta com a matéria natural como uma força natural. Ele põe em movimento as forças naturais pertencentes s sua corporeidade, braços, pernas, cabeça e mãos, a fim de se apropriar da matéria natural numa forma útil a própria vida. Ao atuar, por meio desse movimento, sobre a natureza externa a ele e ao modificá-la, ele modifica, ao mesmo tempo, sua própria natureza (MARX, 1983, p. 149).
}

A partir do pensamento de Marx, de que o ser social se faz pelo e no trabalho, compreendemos que suas dimensões fudamentam-se nos elementos necessários à vida biológica, cultural, comunitária, estética, simbólica, lúdica e afetiva. Ao considerar essas múltiplas dimensões, o trabalho torna-se a categoria central para a formação humana em sua relação com a formação profissional. Tomamos, então, a ideia de trabalho formativo ou educativo - o Trabalho como Princípio Educativo - no que se refere às técnicas didáticas ou metodológicas no processo de ensino e aprendizagem, bem como um princípio ético e político, tal qual refletem os pesquisadores dessa categoria formativa.

Um dos espaços constituídos oficialmente para concretude de tais processos educativos são os IFs, que a partir do decreto n 5.154/04 (BRASIL, 2004), possibilitaram a articulação entre a Educação Profissional e o Ensino Médio por meio da oferta da Educação Profissional Técnica de Nível Médio, na sua forma integrada, entendida na perspectiva da 
Revista do Programa de Pós-Graduação em Educação da Unochapecó ISSN 1984-1566 (on-line) ISSN 1415-8175 (impressa)

formação Omnilateral ${ }^{5}$ e Politécnica. Esses espaços educacionais dizem respeito à formação humana

[...] política, social, cultural, ética e estética, oposta a um treinamento unilateral e instrumental do aprender a fazer, provocada pelo trabalho alienado, pela divisão social e técnica do trabalho, somadas pelas relações burguesas de exploração da classe trabalhadora (SOUSA JÚNIOR, 2008, p. 284).

Uma vez consideradas as dimensões ontológica e histórica do trabalho, enquanto princípio educativo, é importante enfatizar que não se trata simplesmente preparação direcionada para o emprego e inserção no mercado. Ultrapassa o seu sentido estritamente econômico, consolidando uma proposta de formação omnilateral

Ramos (2005) expõe que essa dimensão educacional propicia aos sujeitos acesso aos conhecimentos e à cultura construídos pela humanidade, à realização de escolhas e à construção de caminhos para a produção da vida. Esse caminho, enfatiza a autora, é o trabalho.

Considerar o trabalho como princípio educativo equivale dizer que o ser humano é produtor de sua realidade e, por isto, se apropria dela e pode transformá-la. Equivale dizer, ainda, que nós somos sujeitos de nossa história e de nossa realidade. Em síntese, o trabalho é a primeira mediação entre o homem e a realidade material e social (RAMOS, 2005, p.3).

Ramos (2005), nos apresenta dois pilares conceituais constitutivos da Educação Integrada: a Escola Unitária, para a superação da dicotomia do modelo dual - característica da educação no Brasil - garantindo a todos o direito ao conhecimento; e uma educação politécnica, que possibilita o acesso à cultura, à ciência, ao trabalho, por meio da articulação entre a Educação Básica e a Profissional.

A ideia de formação integrada sugere superar o ser humano dividido historicamente
pela divisão social do trabalho entre a ação de executar e a ação de pensar, dirigir
ou planejar. Trata-se de superar a redução da preparação para o trabalho ao seu
aspecto operacional, simplificado, escoimado dos conhecimentos que estão na sua
gênese científico-tecnológica e a sua apropriação histórico-social. Como formação
humana, o que se busca é garantir ao adolescente, ao jovem e ao adulto trabalhador
o direito a uma formação completa para a leitura do mundo e para a atuação como

${ }^{5}$ A partir dos estudos realizados de Marx sobre educação, Manacorda (2007, p. 19) entende essa formação omnilateral "[...]como a totalidade de capacidades produtivas e, ao mesmo tempo, a totalidade de capacidades de consumo e prazeres, em que se deve considerar, sobretudo o gozo daqueles bens espirituais, além dos materiais, e dos quais o trabalhador tem estado excluído em consequência da divisão do trabalho". 
cidadão pertencente a um país, integrado dignamente à sua sociedade política. Formação que, neste sentido, supõe a compreensão das relações sociais subjacentes a todos os fenômenos (RAMOS, 2005, p.85).

A aludida Escola Unitária foi proposta por Gramsci (1989), que defende a superação dos ambientes estudantis que separam o saber intelectual do prático. Isso objetiva uma consciência social na constituição de atividades que tivessem fins coletivos. Esse princípio unitário da produção humana ultrapassaria os muros das instituições escolares e conjugaria uma integração social maior aliando saber prático e teórico.

O advento da escola unitária significa o início de novas relações entre trabalho intelectual e trabalho industrial não apenas na escola, mas em toda a vida social. $O$ princípio unitário se refletirá, por isso, em todos os organismos de cultura, transformando-os e dando-lhes um novo conteúdo (GRAMSCl, 1989, p. 125).

A escola unitária, nesse viés, tem o trabalho como elemento norteador em todas as suas etapas formativas. Não necessariamente períodos focados num aprendizado fabril para produção mecânica, por exemplo, mas o resultado de atividades eruditas e materiais, mediante as necessidades de uma comunidade.

\footnotetext{
Entender a educação dessa forma implica a compreensão de que a ação humana, ao se concretizar no cotidiano, transforma a realidade vivida, adaptando-a as intenções e aos direcionamentos próprios das necessidades humanas de produzir sua existência. Entre elas, a de superar as mais básicas e fundamentais relacionadas à sobrevivência e que, uma vez satisfeitas, dão lugar a outras no processo de se constituir como ser humano e se manter como tal, o que o coloca diante da necessidade fundamental de aprender como fazer isso (GUIMARÃES, 2016, p.207).
}

A produção do homem, desse modo, precisa ser apropriada por toda coletividade, situando o trabalho como propulsor dessa criação, tanto material quanto imaterial, na multiplicidade dos sentidos e direções, para o fim único da vida social. Em decorrência desse processo, “[...] exige-se um novo princípio educativo na escola em todos os níveis, que tome o trabalho como ponto de partida, concebido mediante atividade teórica/prática, síntese entre ciência técnica e humanismo histórico" (KUENZER, 1989, p. 23).

O trabalho como categoria central para a formação humana, enquanto práxis, contribui para a Educação Libertadora (FREIRE, 1987), uma vez que "[... ] quanto maior o domínio do conteúdo do trabalho pelo profissional, maior sua participação nas decisões 
sobre ele, maior sua autonomia, maiores suas possibilidades de criação" (KUENZER, 1992, p. 115).

Nessa compreensão, as possibilidades formativas presentes nos IFs tornam esse espaço escolar, local privilegiado da consolidação do Ensino Médio Integrado cuja proposta potencializa a articulação de "[... ] cultura, conhecimento, tecnologia e trabalho como direito de todos e condição da cidadania e democracia efetivas (FRIGOTTO, 2005, p. 77)”. As reflexões de Moura (2007) corroboram essa discussão. Ele explicita que:

Essa perspectiva, ao adotar a ciência, a tecnologia, a cultura e o trabalho como eixos estruturantes, contempla as bases em que se pode desenvolver uma educação tecnológica ou politécnica e, ao mesmo tempo, uma formação profissional stricto sensu exigida pela dura realidade da sociedade brasileira (MOURA, 2007, p. 20).

Importa, ainda, nessa discussão, chamar a atenção para transformações que ocorrem com os jovens quando vivenciam a passagem para última etapa da Educação Básica. Nesse particular, àqueles que buscam o acesso aos IFs e que precisam fazer a opção de um curso técnico ofertado, antes do seu ingresso na instituição. Destacamos que tal situação - conjunto de novidades, projeções e opções - ocorre na adolescência que, em termos biológicos, possui uma ordem cronológica delimitada.

\footnotetext{
Parece que a duração da adolescência pode ser razoavelmente definida em termos de processos psicológicos, em face às limitações do emprego de outros elementos. Segundo essa estrutura de referência, a adolescência começa com as reações psicológicas do jovem a suas mudanças físicas da puberdade e se prolonga até razoável resolução de sua identidade pessoal. Para alguns, o processo de maturação sexual pode começar na primeira década da vida e, para outros jamais se conseguirá um firme senso de identidade pessoal. Entretanto, para a maioria das pessoas jovens, estes eventos ocorrerão entre as idades de 11 e 21 anos, que limitam a fase da adolescência (CAMPOS, 2002, p. 15).
}

Recorremos a uma trajetória temporal da definição da adolescência para tratarmos da sua atualidade. Nela entendemos que sua ideia é originária do século XVIII, historicamente relacionada com a época de edificação do capitalismo industrial. Devido à crescente maquinização dos meios de produção e à necessidade de saberes técnicos, os jovens foram paulatinamente sendo separados do processo produtivo de sua família e da comunidade, sendo direcionados à escola, “[...] local onde eles se tornarão ártifices da sua própria fortuna" (ARIÈS, 1978, p. 277 ). 
Além de toda as transformações biológicas, fisiológicas, emocionais e psicológicas, entre outras ligadas às subjetividades do ser jovem, sua inserção numa sociedade culturalmente instituída tende a influenciar na própria constituição e caracterização individuais e, consequentemente, relação com a comunidade. Esses estudos são foco de análise da Psicologia Social. Rodrigues, Assmar, Jablonski (2009) - estudiosos dessa área no Brasil - dialogam, intimamente, com o conceito de adolescência e a complexidade presentes nessa fase da vida. Destacamos como problematizações, respaldados por esses estudos, um desconcerto que está inserido numa construção social na qual vivem os adolescentes, indo além de mera localização etária das pessoas.

\begin{abstract}
A Psicologia Social é o estudo científico da influência recíproca entre as pessoas (interação social) e o processo cognitivo gerado por essa interação (pensamento social). À exceção da figura lendária de Robinson Crusoé e os eremitas, todos nós seres humanos vivemos em constante processo de dependência e interdependência em relação aos nossos semelhantes (RODRIGUES; ASSMAR; JABLONSKI, 2009, p. 13).
\end{abstract}

Os autores acrescentam que determinadas atitudes e comportamentos tomados pelos indivíduos devem ser compreendidos como fruto das relações sociais, das condições de vida e dos valores sociais presentes na cultura. Ou seja, as ações e, notadamente decisões pessoais, são promovidas de acordo com o emaranhado social vivenciado organicamente. Nesses espaços de interações sociais possíveis, o adulto configura-se como uma espécie de exemplo a ser seguido ou repelido, com base na posição que essa geração mais antiga exerce junto ao agrupamento humano específico, bem como na maneira de viver e se relacionar.

Dessa forma, a interação do jovem com as atividades produtivas, compreendidas aqui na dimensão formadora do ser humano, desenvolvidas junto a comunidade e com os adultos responsáveis pela sua realização, constitui-se em elementos indispensáveis na compreensão do trabalho. Esse entendimento considera os aspectos ontológicos e históricos, no sentido mais amplo do que apenas a preparação ao emprego, mas sim, para a escolha da futura formação profissional.

Subsidiado pelos aportes da Psicologia Social, Calligaris (2000) desenvolve um estudo situando o adolescente no mundo contemporâneo, sua relação com a cultura e processo de associações com os adultos. 


\begin{abstract}
Em primeira aproximação, eis então como começar a definir um adolescente. Inicialmente, é alguém: 1 . que teve o tempo de assimilar os valores mais banais e mais bem compartilhados na comunidade (por exemplo, no nosso caso: destaque pelo sucesso financeiro/social e amoroso/sexual); 2. cujo corpo chegou à maturação necessária para que ele possa efetiva e eficazmente se consagrar às tarefas que lhes são apontadas por esses valores, competindo de igual para igual com todo mundo; 3. para quem, nesse exato momento, a comunidade impõe uma moratória (CALLIGARIS, 2000, p. 15).
\end{abstract}

Tomando a adolescência como moratória, Calligaris (2000) analisa as dificuldades que os jovens vão encontrar na sociedade para se inserirem nesta fase, e que, para o autor, só se tornou problemática, quando "[... ] o olhar adulto não reconheceu nelas os sinais da passagem para a vida adulta" (CALLIGARIS, 2000, p.20). Ainda para esse estudioso:

Numa sociedade em que os adultos fossem definidos por alguma competência específica, não haveria adolescentes, só candidatos e uma iniciação pela qual seria fácil decidir: sabe ou não sabe, é ou não é adulto. Como ninguém sabe direito o que é um homem ou uma mulher, ninguém sabe também o que é preciso para que um adolescente se torne adulto. O critério simples da maturação física é descartado. Falta uma lista estabelecida de provas rituais. Só sobram então a espera, a procrastinação e o enigma, que confrontam o adolescente - este condenado a uma moratória forçada de sua vida - com uma insegurança radical (CALLIGARIS, 2000, p.21).

Assim, constituímos ao longo desse texto, possibilidades de aproximações das concepções acerca do Trabalho, Educação e estudos da Psicologia Social no intuito de firmar que a aquisição de conhecimentos historicamente construídos são fundamentais para a inserção dos sujeitos no mundo do trabalho. Mesmo considerando a escola uma instituição produzida e determinada pelas relações sociais de produção, ela é o locus de materialização para uma educação que reitera o sentido da formação humana integral que defendemos.

\title{
2 METODOLOGIA: PROCEDIMENTOS E PERCURSOS DA PESQUISA
}

Adotamos como opção metodológica as orientações da pesquisa qualitativa em consonância com as abordagens da pesquisa intervenção. Nesse procedimento, "[...] as interferências estão destinadas a produzir avanços e melhorias nos processos de 
aprendizagem dos sujeitos que delas participam - e a posterior avaliação dos seus efeitos" (DAMIANI et al. 2013, p. 58).

Com tal direcionamento da pesquisa intervenção, o interesse é a análise de instituições mediante investigação de campo que mediem os saberes teóricos e técnicos com as realidades sócio-políticas dos diferentes espaços educacionais no território nacional. "Não há, portanto, o que ser revelado, descoberto ou interpretado, mas criado" (ROCHA; AGUIAR, 2003, p. 72).

Os sujeitos envolvidos foram compostos por dois grupos distintos: os estudantes do $9^{\circ}$ ano que frequentam o Pré Ifes da cidade de Cachoeiro de Itapemirim - ES, na faixa etária dos 13 aos 15 anos e os servidores do Grupo Gestor do Ifes localizado na mesma cidade. O citado grupo é composto por profissionais que atuam diretamente no curso escolhido - Técnico Integrado em Informática - e com as ações do projeto de extensão Ifes Portas Abertas. Para a produção dos dados, fizemos as opções pelo questionário e pela entrevista, a fim de valorizar a escuta junto aos participantes da investigação. Em todo o percurso da pesquisa empírica, um Diário de Campo foi organizado pelos pesquisadores.

$\mathrm{Na}$ primeira etapa do trabalho de campo lançamos mão do Questionário Diagnóstico ${ }^{6}$ aos 140 estudantes que frequentaram as aulas no curso preparatório Pré-Ifes. Objetivamos conhecer seus motivos para escolha do Ifes campus Cachoeiro de Itapemirim para sequenciamento dos seus estudos no Ensino Médio, o curso desejado, suas perspectivas de futuro e dúvidas em geral, especificamente quanto às possibilidades de colocação profissional na região sul do Estado do Espírito Santo. Essa ação ocorreu nas instalações do próprio Pré-Ifes, antes de participarem da atividade de extensão "Ifes Portas Abertas" no campus de Cachoeiro de Itapemirim.

Nos chamaram a atenção as dúvidas dos alunos referentes ao mundo do trabalho na área de atuação dos Técnicos em Informática formados no instituto, somado ao fato desse ser o itinerário formativo de maior procura nos processos seletivos dos últimos três anos no campus cachoeirense. Nesse contexto, planejamos, executamos e avaliamos uma intervenção pedagógica junto ao "Ifes Portas Abertas", no formato de Oficina de Orientação Profissional.

\footnotetext{
${ }^{6}$ Questionário inspirado em Balbinotti e Tétreau (2006), com aproximações metodológicas aos trabalhos de Munhoz e Melo Silva (2011) e Ferreira e Costa (2014).
} 
REVISTA

Revista do Programa de Pós-Graduação em Educação da Unochapecó

ISSN 1984-1566 (on-line) ISSN 1415-8175 (impressa)

Imposta salientar que as atividades pedagógicas - componentes da citada oficina foram formuladas tendo como parâmetro a experiência realizada na Feira de Profissões da Universidade de São Paulo por Fonçatti et al (2016). Com essas indicações, a prática educativa proposta consistiu nos procedimentos apresentados no Quadro 1:

Quadro 1: Procedimentos metodológicos da pesquisa

1. Elaboração de um diagnóstico situacional por meio da investigação do curso Pré-Ifes cachoeirense e da atividade de extensão "Ifes Portas Abertas"
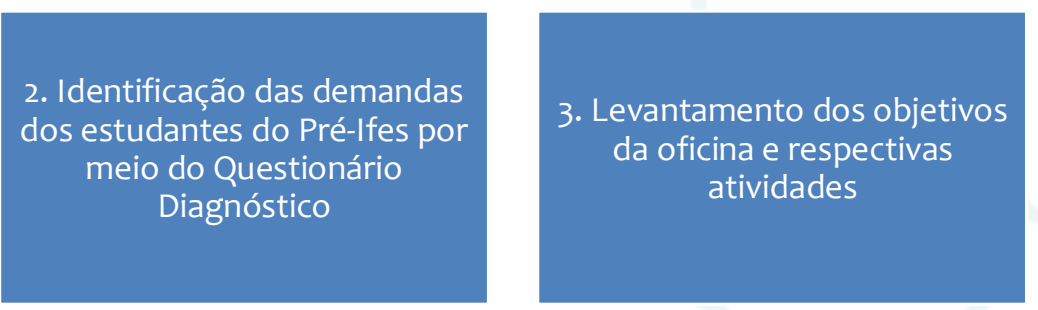
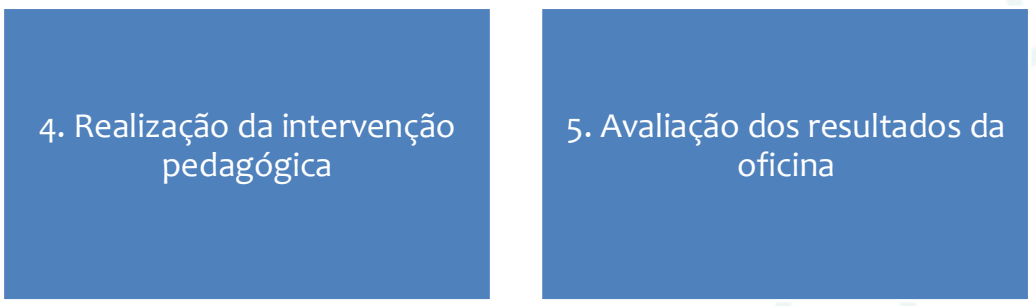

Fonte: Elaborado pelos autores (2019).

As etapas que compõem a experiência pedagógica foram organizadas e desenvolvidas em momentos específicos e elaboradas pelos pesquisadores. Para a concretização da penúltima etapa - Realização da intervenção pedagógica - contamos com a participação dos profissionais da área de Informática que exercem atividades laborais no Sul do Espírito Santo que, de forma voluntária, colaboraram na feitura da estratégia de intervenção. A interação junto aos estudantes foi norteada pelas seguintes abordagens: 
Quadro 2: Roteiro da Oficina de Orientação Profissional

\section{Identificação pessoal}

Local de formação e exercício profissional atual

Experiência profissional na área de Informática

Realidade salarial

Influência da formação técnica em Informática quanto

a ação cidadã (foco na importância social e política)

Fonte: Elaborado pelos autores (2019).

Após a efetivação da intervenção pedagógica os 32 estudantes presentes na atividade proposta responderam a um segundo questionário, complemento do Questionário Diagnóstico, que averiguou se as dúvidas que possuíam foram sanadas. Ressaltamos que a participação, nesse segundo momento, foi específica aos indivíduos interessados no curso Técnico em Informática.

Outra ação foi realizar as entrevistas, no formato semiestruturado, com o Grupo Gestor do Ifes cachoeirense. Como esses sujeitos do Grupo Gestor não estiveram presentes no momento da implementação da prática educativa, disponibilizamos o Diário de Campo para que se municiassem de informações sobre os processos que envolveram o planejamento das propostas de intervenção, sua execução e avaliação. Foram feitos contatos prévios junto a esses servidores para a entrega individualizada do material produzido e agendamos o dia das entrevistas para sua posterior realização.

\section{RESULTADOS E DISCUSSÕES}

Voltamos-nos, nessa etapa, à exploração das experiências produzidas durante a inserção no campo da pesquisa e nos atemos àquelas relativas ao mundo do trabalho, expostas pelos estudantes que pleitearam o curso técnico integrado em Informática. $\mathrm{O}$ campo da pergunta do Questionário Diagnóstico “Onde e como trabalhar depois de 
formado" foi o segundo mais assinalado pelos estudantes, quando perguntados pelo motivo de escolherem o Ifes como local de prosseguimento dos estudos. Entretanto, na indagação subsequente - "Você sabe o local onde o técnico formado na área de Informática trabalha?" - cerca de 70\% não soube responder, somados a 74\% que alegaram a necessidade de acesso a essa informação para escolha do curso pretendido.

Após a participação da intervenção pedagógica, 100\% dos estudantes destacaram sua satisfação em ter participado de tal experiência educativa e sua importância nessa etapa de escolha do curso no Ifes. Nesse sentido, cerca de $97 \%$ disseram que os diálogos estabelecidos durante a atividade, ajudaram no entendimento das possibilidades de trabalho de um técnico em Informática em várias áreas de atuação.

Os depoimentos a seguir corroboram os dados expostos acima: "Com isso nós descobrimos como trabalhar no futuro, quando acabarmos o ensino do Ifes" (Estudante 01); O Estudante 02 afirmou ser “[... ] importante mostrar áreas de trabalho" e o Estudante 03: "Porque vamos saber mais coisas sobre o mercado de trabalho e termos a certeza do caminho que queremos seguir".

Ao serem indagados sobre as possibilidades salariais da profissão escolhida, $84 \%$ dos adolescentes responderam que não tinham informações acerca da realidade salarial do técnico formado em Informática, e, 71\% deles informaram ser relevante esse dado para o momento de fazer a opção do curso.

Logo depois da participação na experiência pedagógica, 84\% destacaram que as atividades desenvolvidas esclareceram a respeito das possibilidades de remuneração dos profissionais, além de considerarem esses dados de muita importância para a escolha do curso. Apresentamos alguns depoimentos: "Porque eu quero muito um trabalho e essas informações nos animam” (Estudante 12); “Pois com isso ajuda a saber em qual área me especializar" (Estudante 09) e “É bom saber quanto um técnico ganha” (Estudante 05).

Quando inquiridos, primeiramente por meio do Questionário Diagnóstico, quanto à importância das informações referentes ao curso e o seu papel na formação de um profissional com atuação política cidadã, $71 \%$ dos discentes afirmaram não ter esse conhecimento e nem sabem fazer essa relação com a formação para a cidadania. $82 \%$ destacaram que essas informações veiculadas à formação cidadã seriam fundamentais 
para o real entendimento do papel e empoderamento de tais profissionais junto a comunidade na qual vive.

No segundo momento da interpelação a respeito dessa temática, 90\% dos participantes ressaltaram que as explanações dos profissionais, suas respostas e exemplos dados durante as conversas esclareceram muito a respeito da relação "curso de Informática e a formação cidadã”. $78 \%$ expuseram sobre a importância de conhecer essa realidade. Seguem alguns excertos: "Pois com isso, soube um pouco mais do papel desse profissional na sua atuação na sociedade em geral", expôs o Estudante 05; "Saber onde desempenho meu papel como técnico em Informática e como posso contribuir para a sociedade é muito bom", depôs o Estudante 01 e "Pelo motivo de que a informática hoje está em todos os lados e a nossa responsabilidade nisso", esclareceu o Estudante 08.

Quando sondados inicialmente com relação às diversas possibilidades de atuação nessa área profissional e a importância dessa discussão no momento da participação do projeto do Ifes Portas Abertas, 97\% dos alunos alegaram esperar abordagens desse contexto. Posteriormente, para 93\%, as atividades realizadas durante a experiência pedagógica deveriam compor a apresentação do campus, ressaltando discursivamente: "Pois é muito importante para as pessoas que não têm um conhecimento muito aprofundado nessa área e vão ter a partir dessa oficina” (Estudante 05); “Pois ela ajuda a conhecer sobre o mercado de trabalho e como trabalhar" atesta o Estudante 07 e "Para todos conhecerem e entenderem o que um Técnico em Informática faz", afirma o Estudante 12.

O Grupo Gestor do Ifes campus Cachoeiro de Itapemirim foi envolvido no momento da produção dos dados a partir da análise do Diário de Campo. Nesse documento, sistematizamos os movimentos da pesquisa e a intervenção pedagógica, sendo entregue antecipadamente, conforme já indicamos. O material subsidiou os servidores na ocasião da entrevista, que nesse ínterim, apontaram que as atividades desenvolvidas consistiram em “Uma boa estratégia por focar no desenvolvimento humano a partir do trabalho" (Gestor 01); “[... ] uma prática pedagógica com futuro promissor” considerou o Gestor 02 e "Um momento bom e interessante", expôs o Gestor 03.

De modo geral, os profissionais validaram a oficina, reconheceram o seu valor e entendimento da urgência da sua aplicabilidade com a imediata incorporação ao projeto já 
desenvolvido. Todavia, chamaram a atenção para aspectos relacionados à sua concretude diante do acúmulo de tarefas no âmbito da gestão e atividades de sala de aula, como também, a respeito do grande quantitativo dos participantes do Ifes Portas Abertas.

$\mathrm{Na}$ direção de responder tais problematizações, foi produzido, além do roteiro da Oficina de Orientação Profissional, um vídeo institucional para apresentação no instante da participação estudantil no Ifes Portas Abertas, que substitui as atividades com presença dos profissionais convidados e permite sua atualização periodicamente. Com o objetivo de não perdermos a interação entre técnicos e estudantes, considerado pelos entrevistados como o ponto alto da experiência realizada, esses especialistas se dispuseram a responder todas as eventuais dúvidas dos adolescentes mediante contato dos interessados. Assim sendo, veiculamos também um endereço virtual para troca de mensagens, porém, sob a administração de profissionais do Ifes.

Estamos certos de que contribuímos para discussões e direcionamentos práticos para resoluções dos problemas destacados nessa pesquisa, porém, entendemos que esse estudo não está acabado e deve ser revisitado por pesquisadores contemporâneos e futuros.

\section{CONSIDERAÇÕES FINAIS}

$\mathrm{Na}$ tessitura desse texto, não desconsideramos a crise estrutural e cíclica do capitalismo, momento em que o modo de produção financeiro especulativo concretiza “[...] um sistema de metabolismo antissocial do capital cuja normalidade é a destrutividade" (ANTUNES,2020 p. 12), como também não ignoramos a crise sanitária instalada com a pandemia do Coronavírus SARS - CoV-2 (Covid-19) que, cotidianamente, dizima milhares de vidas humanas.

Tampouco deixamos de ter em conta os atravessamentos do projeto neoliberal na conjuntura educacional brasileira, junto ao consequente desmantelamento das políticas sociais e os efeitos nefastos da reforma trabalhista, a exemplo da precarização das relações e das condições de trabalho no campo e na cidade.

Optamos, na produção do texto, evidenciar a centralidade do trabalho no seu duplo sentido: práxis humana e produtiva, em interlocução com os estudos sócio-históricos da 
Psicologia Social, que concebe a adolescência como produção social. Com esses aportes, explicitamos a experiência pedagógica, realizada no âmbito do Mestrado em Educação Profissional e Tecnológica, desenvolvida de forma colaborativa com os gestores do Ifes e profissionais da área de Informática da iniciativa privada da região de Cachoeiro de Itapemirim - ES. Intentamos subsidiar as escolhas estudantis num momento ímpar de sua constituição enquanto ser humano, que necessita optar para o prosseguimento de suas trajetórias educativas. Decisões que vão delinear seu futuro concernente à sua carreira profissional.

Vale também ressaltar que nossa inserção ao campo empírico nos deu pistas para a construção do roteiro da prática pedagógica, desenvolvida e avaliada junto aos discentes, bem como à produção do vídeo institucional, material educativo disponível para ser utilizado atualmente pelos gestores responsáveis pelo desenvolvimento do projeto de extensão Ifes Portas Abertas. Essas ações, produzidas no âmbito do movimento da pesquisa, potencializaram essa ação extensionista e contribuíram com as escolhas dos educandos no seu percurso de escolarização profissional técnica.

A prática docente desenvolvida, nesse particular, comprometida com os princípios da Pedagogia Histórico-Crítica (SAVIANI, 2013, p. 80), possibilita “[...] uma proposta pedagógica cujo ponto de referência, cujo compromisso, seja a transformação da sociedade e não sua manutenção, a sua perpetuação". Essa perspectiva se aproxima à formação humana omnilateral e os pressupostos do pensamento freiriano de Educação Libertadora. À luz desse pensamento, entendemos que o debate pautado na reflexão crítica aponta para a afirmação da autoconfiança dos estudantes, na medida em que potencializa a emancipação e seu protagonismo. Trata-se, portanto, de reconhecer a ausência de neutralidade, o efetivo e permanente papel político da escola e do(a) educador(a) em sua práxis educativa.

A postura ético-política dos educadores, em seu comprometimento com a histórica luta de classes, revela-se também por meio do movimento permanente do repensar e inovar as estratégias pedagógicas, ressignificando o papel da escola no âmbito da proposta de formação humana integral. Tais certezas centralizam o trabalho para além da integração de níveis educacionais distintos, na direção da humanização do homem e fortalecimento da coletividade. 
Revista do Programa de Pós-Graduação em Educação da Unochapecó

ISSN 1984-1566 (on-line) ISSN 1415-8175 (impressa)

\section{REFERÊNCIAS}

ANTUNES, Ricardo. Coronavírus: o trabalho sob fogo cruzado. São Paulo: Boitempo, 2020.

ARIÈS, Philippe. História social da criança e da família. Tradução de D. Flaksman. 2. ed. Rio de Janeiro: LTC, 1978.

BALBINOTTI, Marcos Alencar Abaide; TETREAU, Bernard. Questionário de educação à carreira: propriedades psicométricas da versão brasileira e comparação transcultural. Revista brasileira de orientação profissional, São Paulo, v. 7, n. 2, p. 49-66, 2006. ISSN 1984-7270. Disponível em:

http://pepsic.bvsalud.org/scielo.php?script=sci_arttext\&pid=\$1679-33902006000200006. Acesso em: 13 maio de 2021.

BRASIL. Lei n 9.394 de 20 de dezembro de 1996. Estabelece as diretrizes e bases da educação nacional. Diário Oficial [da] República Federativa do Brasil. Brasília, 20 dez. 1996. Disponível em: http://www.planalto.gov.br/ccivil_03/leis/l9394.htm. Acesso em: 10 jun. 2019.

BRASIL. Decreto n. 5.154 de 23 de julho de 2004. Regulamenta o $\$ 20$ do art. 36 e os arts. 39 a 41 da Lei no 9.394, de 20 de dezembro de 1996, que estabelece as diretrizes e bases da educação nacional, e dá outras providências. Diário Oficial [da] República Federativa do Brasil. Brasília, 23 julho. 2004. Disponível em:

http://www.planalto.gov.br/ccivil_03/_ato2004-2006/2004/decreto/d5154.htm. Acesso em: 22 out. 2018.

BRASIL. Lei no 11.892 de 29 de dezembro de 2008. Institui a Rede Federal de Educação Profissional, Científica e Tecnológica, cria os Institutos Federais de Educação, Ciência e Tecnologia, e dá outras providências. Diário Oficial [da] República Federativa do Brasil. Brasília, 29 dez. 2008. Disponível em: http://www.planalto.gov.br/ccivil_03/_ato20072010/2008/lei/l11892.htm. Acesso em: 23 jul. 2019.

BRASIL. Ministério da Educação. Secretaria de Educação a Distância. Salto para o futuro: juventude e escolarização: os sentidos do Ensino Médio. Brasília, 2009. Disponível em: http://portaldoprofessor.mec.gov.br/storage/materiais/0000012176.pdf. Acesso em: 07 dez. 2020.

BRASIL. Ministério da Educação. Catálogo nacional de cursos técnicos. Brasília: MEC, 2016. Disponível em: http://portal.mec.gov.br/docman/novembro-2017-pdf/77451-cnct-3aedicao-pdf-1/file. Acesso em: 21 ago. 2019.

CALLIGARIS, Contardo. A adolescência. São Paulo: Publifolha, 2000.

CAMPOS, Dinah Martins de Souza. Psicologia na adolescência. 22. ed. Petrópolis: Editora Vozes, 2002. 
Revista do Programa de Pós-Graduação em Educação da Unochapecó ISSN 1984-1566 (on-line) ISSN 1415-8175 (impressa)

CARCANHOLO, Reinaldo. Capital: essência e aparência. São Paulo: Expressão Popular, 2011.

DAMIANI, Magda Floriana et.al. Discutindo pesquisas do tipo intervenção pedagógica. Cadernos de Educação, Pelotas/RS, n. 45, p. 57- 67, maio/ago. 2013. Disponível em: https://periodicos.ufpel.edu.br/ojs2/index.php/caduc/article/view/3822. Acesso em: 13 maio de 2021.

FERREIRA, Gisele Vieira; COSTA, Elenise Martins. Workshop de orientação profissional em escolas públicas. Psicologia.pt, 2014. Disponível em: https://www.psicologia.pt/artigos/ver_artigo.php?workshop-deorientacao\%20profissional-em-escolas-publicas\&codigo=A0800\&area=d7. Acesso em: 03 nov. 2018.

FONÇATTI, Guilherme et al. Oficina de orientação profissional: construindo estratégias de intervenção para feira de profissões. Revista Brasileira de Orientação Profissional, São Paulo, v. 17, n. 1, p. 103-113, jan./jun. 2016. Disponível em:

http://pepsic.bvsalud.org/pdf/rbop/v17n1/11.pdf. Acesso em: 13 maio 2021.

FREIRE, Paulo. Pedagogia do oprimido. 2. ed. Rio de Janeiro: Paz e Terra, 1987.

FRIGOTTO, Gaudêncio. Concepções e mudanças no mundo do trabalho e o ensino médio. In: FRIGOTTO, Gaudêncio.; CIAVATTA, Maria.; RAMOS, Marise. (Org.). Ensino médio integrado: concepção e contradições. São Paulo: Cortez, 2005, p. 57-82.

GRAMSCI, Antonio. Concepção dialética da história. 8. ed. Rio de Janeiro: Civilização Brasileira, 1989.

GUIMARÃES, Ailton Vitor. Trabalho e educação profissional e tecnológica. Revista Pedagógica, Chapecó, v. 18, n. 39, p. 196-228, set./dez. 2016. Disponível em:

https://bell.unochapeco.edu.br/revistas/index.php/pedagogica/article/view/3622. Acesso em: 13 maio de 2021.

INSTITUTO FEDERAL DO ESPÍRITO SANTO. Plano de Desenvolvimento Institucional. Vitória: Instituto Federal do Espírito Santo, 2019. Disponível em:

https://www.ifes.edu.br/images/stories/Res_CS_48_2019__PDI__Anexo.pdf. Acesso em: 19 abr. 2021.

INSTITUTO FEDERAL DO ESPÍRITO SANTO. Ifes Portas Abertas 2009. Cachoeiro de Itapemirim: Instituto Federal do Espírito Santo, 2019. Disponível em: https://cachoeiro.ifes.edu.br/noticias/16465-ifes-portas-abertas-2019. Acesso em: 10 jul. 2019.

KOSIK, Karel. Dialética do concreto. Rio de Janeiro: Paz e Terra, 1976. 
Revista do Programa de Pós-Graduação em Educação da Unochapecó ISSN 1984-1566 (on-line) ISSN 1415-8175 (impressa)

KUENZER, Acácia Zeneida. Ensino de $2^{\circ}$ Grau: o trabalho como princípio educativo. São Paulo: Cortez, 1992.

KUENZER, Acácia Zeneida. O trabalho como princípio educativo. Cadernos de Pesquisa, São Paulo, n. 68, p. 21-28, fev. 1989. Disponível em:

http://publicacoes.fcc.org.br//index.php/cp/article/view/1118. Acesso em:10 nov. 2018.

MANACORDA, Mario Alighiero. Marx e a pedagogia moderna. Campinas: Alínea, 2007.

MARX, Karl. O capital. V. I, tomo 1. São Paulo: Abril Cultural, 1983.

MARX, Karl; ENGELS, Friedrich. A ideologia alemã. Tradução de Rubens Enderle, Nélio Schneider e Luciano Cavini Martorano. São Paulo: Boitempo, 2007.

MOURA, Dante Henrique. Educação básica e educação profissional: dualidade histórica e perspectivas de integração. In: Reunião Anual da Associação Nacional de Pós-Graduação e Pesquisa em Educação, 30, 2007, Caxambú. Anais... Caxambu: ANPED, 2007. Disponível em: https://anped.org.br/sites/default/files/gtog-3317-int.pdf. Acesso em 06/05/2021. Acesso em: 13 maio de 2021.

MÜLLER, M. Orientação vocacional: contribuições clínicas e educacionais. Porto Alegre: Artes Médicas, 1988.

MUNHOZ, Izildinha Maria Silva; MELO-SILVA, Lucy Leal. Educação para a Carreira: concepções, desenvolvimento e possibilidades no contexto brasileiro. Revista brasileira orientação profissional, São Paulo, v. 12, n. 1, p. 37-48, jun. 2011 . Disponível em: http://pepsic.bvsalud.org/scielo.php?pid=S1679-

33902011000100006\&script=sci_abstract\#: :text=MUNHOZ\%2C\%20lzildinha\%20Maria\%20Si Iva\%20e, Rev.\&text=A\%20Educa\%C3\%A7\%C3\%A30\%20para\%20a\%20Carreira, de\%20educa\%C3\% A7\%C3\%A30\%2C\%20em\%20muitos\%20pa\%C3\%ADses. Acesso em: 23 jul. 2019.

RAMOS, Marise. Possibilidades e Desafios na Organização do Currículo Integrado. In: FRIGOTTO, G.; CIAVATTA, M.; RAMOS, M. (Orgs). Ensino Médio Integrado: concepção e contradições. São Paulo: Cortez, 2005.

ROCHA, Marisa Lopes da; AGUIAR, Kátia Faria de. Pesquisa-intervenção e a produção de novas análises. Psicologia Ciência e Profissão, Brasília, v. 23, n. 4, p. 64-73, dez. 2003. Disponível em: https://www.scielo.br/scielo.php?pid=S1414-

98932003000400010\&script=sci_abstract\&tlng=pt. Acesso em: 13 maio de 2021.

RODRIGUES, Aroldo.; ASSMAR, Eveline Maria Leal; JABLONSKI, Bernardo. Psicologia social. 27. ed. Petrópolis: Vozes, 2009.

SAVIANI, Dermeval. Pedagogia histórico-critica: primeiras aproximações. 11. ed. São Paulo: Autores Associados, 2013. 
SOUSA JUNIOR, Justino de Souza. Omnilateralidade. In: PEREIRA, Isabel Brasil; LIMA, Júlio César França. Dicionário da educação profissional em saúde. 2. ed. rev. ampl. Rio de Janeiro: EPSJV, 2008.

Recebido em: 24-03-2021

Aprovado em: 21-05-2021

Publicado em: 24-05-2021 